Int. J. Electrochem. Sci., 13 (2018) 3200 - 3209

\title{
Quantum Chemical Assessment of Two Natural Compounds: Vasicine and Vasicinone as Green Corrosion Inhibitors.
}

\author{
Jeetendra Bhawsar ${ }^{1}$, Preeti Jain ${ }^{1}$, M. G. Valladares-Cisneros ${ }^{2, *}$, C. Cuevas-Arteaga ${ }^{3}$, Mukta Rani \\ Bhawsar ${ }^{4}$ \\ ${ }^{1}$ Department of Chemistry, Medi-Caps University, Indore, 452001, (M.P.), India \\ ${ }^{2}$ Facultad de Ciencias Químicas e Ingeniería, Universidad Autónoma del Estado de Morelos, Av. \\ Universidad 1001, Col. Chamilpa, C.P. 62209, Cuernavaca, Mor., México. \\ ${ }^{3}$ Centro de Investigación en Ingeniería y Ciencias Aplicadas, Universidad Autónoma del Estado de \\ Morelos, Av. Universidad 1001, Col. Chamilpa, C.P. 62209, Cuernavaca, Mor., México. \\ ${ }^{4}$ Department of Chemistry, Sri Aurobindo Institute of Technology, Indore, 453111 (M.P.), India \\ *E-mail: $\underline{\text { mg.valladares@uaem.mx }}$
}

doi: $10.20964 / 2018.04 .57$

Received: 1 September 2017 / Accepted: 14 February 2018 / Published: 6 March 2018

A theoretical study has been performed on the main Vasicine and Vasicinone molecules found in Adhatoda vasica plant extract using the Density Functional Theory (DFT). Through this study, the inhibitive effect of these two molecules to reduce the corrosion rate of mild steel in acidic medium is elucidated. The parameters such as dipole moment $(\mu), E_{H O M O}, E_{L U M O}$, energy gap $(\Delta E)$, global hardness $(\eta)$, chemical softness $(\mathrm{S})$, electron affinity (A), ionization potential (I), the absolute electronegativity $(\chi)$, the fraction of electron transfer from the inhibitor molecule to the metallic atom $(\Delta N)$ and Mulliken charges have been calculated. All calculations have been carried out taking into account the Density Functional Theory (DFT) using the GAUSSIAN 03W computational program. The results showed that Vasicinone molecule is favorably adsorbed on the metal surface $(\mathrm{Fe})$ through the electronegative density atoms as active centers of adsorption, and the theoretical conclusions were found to be in agreement with the experimental reported data.

Keywords: Green Corrosion inhibitors; Vasicine; Vasicinone; Quantum Chemical Assessment, Density Functional Theory.

\section{$\underline{\text { FULL TEXT }}$}

(C) 2018 The Authors. Published by ESG (www.electrochemsci.org). This article is an open access article distributed under the terms and conditions of the Creative Commons Attribution license (http://creativecommons.org/licenses/by/4.0/). 